\title{
A Missing Link on Entrepreneurship Education Curricula
}

\author{
Kriswanto Widiawan \\ Department of Industrial Engineering, Petra Christian University, Surabaya, Indonesia \\ kriswidi@petra.ac.id
}

\begin{abstract}
Indeed, there are many failure cases in entrepreneurs' life. The psychological effects of business failure may produce shame and dysfunctional behavior responses. Do the entrepreneurs consider about the potential of shame they face? Do entrepreneurship education institutions pay attention to business closing as well as its impact to entrepreneurs' identity? This research explored the curricula of 66 top business schools which have entrepreneurship specialization. There was a course category, namely self-development, which is important for entrepreneurs to build their mental, self-leadership, self-awareness, self-image, etc. Unfortunately, from 2908 courses offered, only $12.76 \%$ courses were related to entrepreneurship and $0.79 \%$ courses to self-development issues. The curricula were dominated by business knowledge and business skills. There was a missing link, i.e., "when the business goes wrong", how to cope with failure, how to overcome shame, guilt, depression, stress, etc. In conclusion, there were lacks of self-development courses in the entrepreneurship education programs. This paper recommends to prepare the students to anticipate and overcome the shame by adding more psychological-related courses in the curriculum.
\end{abstract}

Keywords: Entrepreneurship Education, Business Failure, Overcome the Shame.

\section{Introduction}

Failures in business are common phenomena in the entrepreneurs' life. Failure is not an option, it is a necessity. Sahlman stated that the failure rate of professional venture firms over the past 15 years has been around 60\%, up from $35 \%$ in the 1980s [1]. In fact, when people cannot meet the standards, rules, and goals, they may feel shame and guilt. Bedford and Hwang defined shame phenomenological as "the feeling of loss of standing in the eyes of oneself or significant others that can occur as the result of a failure to live up to expectations of a person on one's role or status" [2]. The psychological effects of such feelings may produce dysfunctional behavior and various negative responses ranging from withdrawal (leaving the setting and the experience), depression, rage, and attack of others or oneself. Drunk (alcoholism), suicide, consuming drugs (drug addicted) are some examples of attacks on oneself.

The facts on failure and its impact to generate shame bring us into questions: Do entrepreneurs consider about the potential of shame they face? Do entrepreneurship education institutions pay attention to the probability of business closing? Are those institutions aware of feeling shame faced by the entrepreneurs as well as its impact to their identity? This research will explore the curricula of top business schools worldwide to assess whether or not their curricula have prepared courses on psychological aspects of entrepreneurs. By understanding the impact on failedentrepreneurs and the facts on business schools' curricula, this paper will recommend the support needed to help the students handle the shame after business closing.

\section{Theory and Methodology}

Several aspects of shame have been studied, such as the shame and ideal self [3] and a sociological theory of shame
[4]. Regarding specific ethnic study of shame, Bedford and Hwang suggested a cross-cultural framework on guilt and shame in Chinese culture [2]. Since shame is a universal feeling that can be experienced by anybody who fails in his/ her endeavor, Poulson associated shame with an individual's workplace [5]. More specific to entrepreneurs, while Wright and Zahra looked at the dark side of entrepreneurship [6], Smith and McElwee developed a conceptual script-based model of shame in narratives of entrepreneurs in crisis [7].

Related to this paper's objective to prepare young entrepreneurs through entrepreneurship education, I refer to the cognitive shame model suggested by Poulson [5], who depicted shame as an emotion and elaborated how the outcomes of shame are triggered in individuals. Poulson's model is the most comprehensive because it views the shame in relation to the causes, the culture and the value systems of society. In addition, Wright and Zahra [6] and Smith and McElwee [7] contributed in elaborating the entrepreneurs' situation after the failure.

When the entrepreneurs evaluate themselves based on available standards, goals and rules, they may experience success as well as failure. While experiencing success may drive them into either hubris (for global attribution of self) or pride (for specific attribution of self), experiencing failure may bring them into either shame (for global attribution of self) or guilt (for specific attribution of self). The negative aspects of shame after failure, according to Smith and McElwee [7], include tragedy, personality disorders, status anxiety, self-centeredness, destructive relationships, alcoholism, and the most heinous of all, suicide. The report of a working group, organized by the WHO Regional Office for Europe in 1973, mentioned that alcoholism and drug addiction were seen as concomitant forms of self-destructive behavior [8]. "Suicide and attempted suicide as well as selfinflicted injuries specified as intentional" are classified as suicide in the International Classification of Diseases [9]. 
By knowing those negative consequences of failure, potential entrepreneurs may feel fear of being failed. Even in the US, where elaborate support systems are matched by a supportive culture and value system in the society, the fear of failure rates increase from $21 \%$ to $28 \%$ during $2001-2010$ decade [10]. The fear of failure rate is the percentage of population at the age of 18-64 who indicate that fear of failure would prevent them from setting up a business.

What happen in other countries which do not have those good support systems? How about either Asian, African, or Latin America countries that differ from Western countries? The rates measuring the fear of failure in Japan have increased substantially every year, from $22 \%$ in 2001 to $51 \%$ and $50 \%$ in 2008 and 2009 respectively, compared to Peru $(23-34 \%)$ and the US $(18-28 \%)$ in the 2001-2010 decade [10]. The fear of failure rates in France, Hungary, Denmark, India, Italy, Israel, Russia, Romania, Spain, Peru, and US have increased in this period as well, but to a lesser extent. On the contrary, the fear of failure rates in Finland, Greece, Hong Kong, Iceland, Jamaica, South Korea, Venezuela, and United Arab Emirates are decreasing. That is why Japan's average of "Total EarlyStage Entrepreneurial Activity" (TEA) is only $3.20 \%$ in the 2001-2010 decade, compared to Peru (30\%) and the US $(10.32 \%)$. TEA is the percentage of $18-64$ population who are either a nascent entrepreneur or owner-manager of a new business [10]. It seems that there is no connection between good support system with the fear of failure rates and TEA rates.

Despite the numerous negative impacts of shame caused by failing in business and entrepreneurs are prone to experience failures several times before succeeding, surprisingly, most business schools around the world teach entrepreneurship assuming a much more optimistic scenario. I reviewed the curricula of MBA programs in the top business schools worldwide. The data were taken from 66 Top MBA programs in entrepreneurship specialization and a few additional business schools from top $200 \mathrm{MBA}$ programs without specialization in entrepreneurship in order to cover the other regions. The regions categorization in QS world rank was used [11]. They were eight business schools from North America Region (US); twenty two business schools from Europe Region (UK 8 MBAs, France 5, Spain 3, and one each from Greece, Sweden, Denmark, Italy, the Netherland, and Switzerland); twenty eight full time MBAs from Asia and Australia (Australia 7, China 6, India 5, Singapore 3, Japan 2, Hong Kong 2, the Philippines 2, and Vietnam 1). There were also four business schools from Middle East and Africa (one each from South Africa, Israel, Lebanon, and Egypt), and another four MBAs from Latin and Central America (Mexico 2, Argentina 1, and Costa Rica 1).

\section{Result}

I collected the courses offered by 66 business schools by visiting their websites, and categorized them into 22 course categories. The categories were determined by the variety of courses. First, we determined only 10 categories as the common specialization of business schools, i.e., Marketing, Management, Entrepreneurship, Innovation, Operation, Finance, Strategy, Decision Making, International Business, and Organization. Since there were a lot of courses outside existing categories, we also created more categories, namely Accounting, Business Environment, Business Skills, Consulting, Quantitative Tools, Technical Tools, Ethics, Economy and Business, Philosophy, Business Policy, Selfdevelopment, and Other Business.

Table 1 shows the number of courses for each category. There were 2908 both core courses and elective courses with 44.06 courses per school in average. Among those courses, 371 courses were in the Entrepreneurship category or 5.62 courses in every business school. This was the largest category with $12.76 \%$ of the total courses, followed by Finance category with $12.72 \%$. Unfortunately, only $0.79 \%$ courses belong to Self-development content. When I analyzed the categories distribution in term of the region of countries, there were different figures as follows. Business schools in Latin and Central America region emphasized on Finance (11.73\%), Business Environment (11.73\%) and Management (11.11\%). MBA programs in Middle East and Africa region focused on Finance (17.49\%), Management $(13.66 \%)$, and Marketing (12.02\%). Moreover, Finance $(13.54 \%)$ was the biggest category in business schools curricula in Asia and Australia region, by some distance compared to other categories. While full-time MBA programs in Europe emphasized on Entrepreneurship (15.04\%) and Finance (12.88\%), MBA programs in North America/US region emphasized on Entrepreneurship $(27.07 \%)$ and Innovation (11.36\%). Therefore, Finance category existed on top of three regions (developing countries), second top of Europe region and third place of North America/US region (developed country). Entrepreneurship category took top place in both Europe and North America/US regions, $13^{\text {th }}$ position in Latin and Central America region, $7^{\text {th }}$ position in Middle East and Africa region, and $4^{\text {th }}$ position in Asia and Australia region.

Table 2 shows the density of Entrepreneurship courses per school per region. North America/US region was emphasizing in entrepreneurship, followed by Europe region.

What have business schools provided to prepare the potential entrepreneurs in facing the high rates of business failure and handling the shame after business closing? Only 23 courses ( 0.35 courses per school) that related to selfimage, self-awareness, self-leadership, psychological-content courses, called as Self-development category (see Table 3 ). This kind of courses would like to touch the core of human, i.e., identity and self-image. Although facing crisis and even failing in business, potential entrepreneurs should keep strong in handling the shame after failure, keep going and performing as real entrepreneurs.

Courses or modules on how to deal with the psychological consequences of failure seemed absent from entrepreneurship curricula with one notable exception as discussed in the course on "The Founder's Dilemma" at Harvard Business School, which was chosen as the best courses 2011 by Inc. Magazine [12]. 'The course's goal is to help the students to be much more informed about those long-term consequences before they make the early choices that can lead to them" [13]. The course instructors were investigating how to prepare young graduates before they become entrepreneurs and how to start again after first new venture failed. This course is also relevant for the students in countries outside the Western world where new venture failures may not be considered as a source of learning. 
Table 1. Courses categorizing on sixty six top business schools' curricula

\begin{tabular}{|c|c|c|c|c|c|c|c|c|c|c|c|c|c|}
\hline Category & total & Ave & percent & L-tot & L-\% & M-tot & M-\% & A-tot & A-\% & E-tot & E-\% & U-tot & U-\% \\
\hline Innovation & 191 & 2.89 & 6.57 & 5 & 3.09 & 4 & 2.19 & 59 & 4.73 & 68 & 8.18 & 55 & 11.36 \\
\hline Business Environment & 149 & 2.26 & 5.12 & 19 & 11.73 & 7 & 3.83 & 59 & 4.73 & 39 & 4.69 & 25 & 5.17 \\
\hline Decision Making & 57 & 0.86 & 1.96 & 6 & 3.70 & 4 & 2.19 & 27 & 2.16 & 11 & 1.32 & 9 & 1.86 \\
\hline Accounting & 104 & 1.58 & 3.58 & 7 & 4.32 & 7 & 3.83 & 47 & 3.77 & 36 & 4.33 & 7 & 1.45 \\
\hline Marketing & 243 & 3.68 & 8.36 & 11 & 6.79 & 22 & 12.02 & 108 & 8.65 & 82 & 9.87 & 20 & 4.13 \\
\hline Organization & 208 & 3.15 & 7.15 & 15 & 9.26 & 11 & 6.01 & 92 & 7.37 & 58 & 6.98 & 32 & 6.61 \\
\hline Management & 228 & 3.45 & 7.84 & 18 & 11.11 & 25 & 13.66 & 106 & 8.49 & 62 & 7.46 & 17 & 3.51 \\
\hline Business Skills & 115 & 1.74 & 3.95 & 11 & 6.79 & 4 & 2.19 & 56 & 4.49 & 30 & 3.61 & 14 & 2.89 \\
\hline Operation & 108 & 1.64 & 3.71 & 9 & 5.56 & 9 & 4.92 & 52 & 4.17 & 27 & 3.25 & 11 & 2.27 \\
\hline Finance & 370 & 5.61 & 12.72 & 19 & 11.73 & 32 & 17.49 & 169 & 13.54 & 107 & 12.88 & 43 & 8.88 \\
\hline Quantitative Tools & 73 & 1.11 & 2.51 & 6 & 3.70 & 5 & 2.73 & 38 & 3.04 & 18 & 2.17 & 6 & 1.24 \\
\hline Consulting & 23 & 0.35 & 0.79 & 4 & 2.47 & 3 & 1.64 & 12 & 0.96 & 1 & 0.12 & 3 & 0.62 \\
\hline Economy and Business & 147 & 2.23 & 5.06 & 9 & 5.56 & 12 & 6.56 & 73 & 5.85 & 34 & 4.09 & 19 & 3.93 \\
\hline Business Policy & 13 & 0.20 & 0.45 & 2 & 1.23 & 1 & 0.55 & 5 & 0.40 & 3 & 0.36 & 2 & 0.41 \\
\hline Philosophy & 8 & 0.12 & 0.28 & 2 & 1.23 & 0 & 0.00 & 3 & 0.24 & 3 & 0.36 & 0 & 0.00 \\
\hline Self Development & 23 & 0.35 & 0.79 & 7 & 4.32 & 0 & 0.00 & 9 & 0.72 & 3 & 0.36 & 4 & 0.83 \\
\hline Strategy & 134 & 2.03 & 4.61 & 2 & 1.23 & 3 & 1.64 & 64 & 5.13 & 36 & 4.33 & 29 & 5.99 \\
\hline Entrepreneurship & 371 & 5.62 & 12.76 & 4 & 2.47 & 9 & 4.92 & 102 & 8.17 & 125 & 15.04 & 131 & 27.07 \\
\hline Ethics & 34 & 0.52 & 1.17 & 2 & 1.23 & 1 & 0.55 & 15 & 1.20 & 9 & 1.08 & 7 & 1.45 \\
\hline International Business & 150 & 2.27 & 5.16 & 2 & 1.23 & 6 & 3.28 & 90 & 7.21 & 37 & 4.45 & 15 & 3.10 \\
\hline Other Business & 38 & 0.58 & 1.31 & 1 & 0.62 & 0 & 0.00 & 6 & 0.48 & 8 & 0.96 & 23 & 4.75 \\
\hline Technical Tools & 121 & 1.83 & 4.16 & 1 & 0.62 & 18 & 9.84 & 56 & 4.49 & 34 & 4.09 & 12 & 2.48 \\
\hline Total & 2908 & 44.06 & 100 & 162 & 100 & 183 & 100 & 1248 & 100 & 831 & 100 & 484 & 100 \\
\hline
\end{tabular}

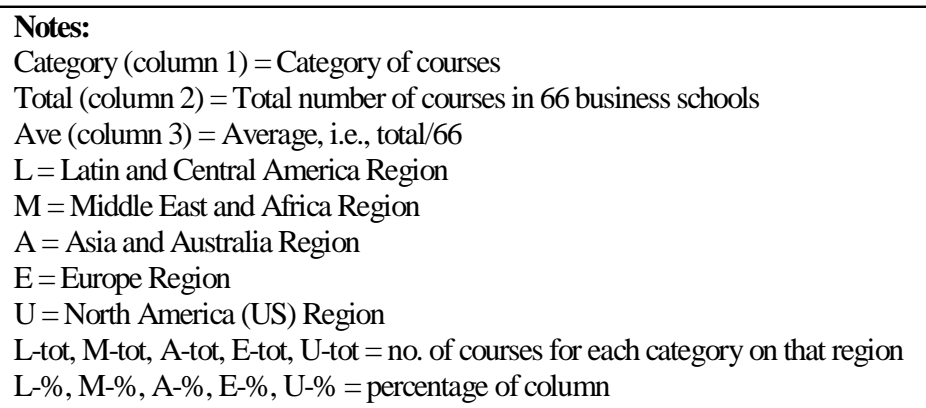

Table 2. Density of entrepreneurship courses per school per region

\begin{tabular}{|c|c|c|c|c|c|c|}
\hline Summary of Entrepreneurship Courses & $\begin{array}{c}\text { North } \\
\text { America }\end{array}$ & Europe & $\begin{array}{c}\text { Asia } \\
\text { Australia }\end{array}$ & $\begin{array}{c}\text { Middle East \& } \\
\text { Africa }\end{array}$ & $\begin{array}{c}\text { Latin \& Central } \\
\text { America }\end{array}$ & Total \\
\hline & 8 Univ. & 22 Univ. & 28 Univ. & 4 Univ. & 4 Univ. & 66 Univ. \\
\hline Total Entrepreneurship Courses & 131 & 125 & 102 & 6 & 7 & 371 \\
\hline Average Entrepreneurship Courses per univ. & 16.38 & 5.68 & 3.64 & 1.50 & 1.75 & 5.62 \\
\hline
\end{tabular}

Table 3. Density of self-development courses per school per region

\begin{tabular}{lcccccc}
\hline \multirow{2}{*}{ Summary of Self Development Courses } & $\begin{array}{c}\text { North } \\
\text { America }\end{array}$ & Europe & $\begin{array}{c}\text { Asia } \\
\text { Australia }\end{array}$ & $\begin{array}{c}\text { Middle East \& } \\
\text { Africa }\end{array}$ & $\begin{array}{c}\text { Latin \& Central } \\
\text { America }\end{array}$ \\
\cline { 2 - 7 } & $\mathbf{8}$ Univ. & 22 Univ. & 28 Univ. & 4 Univ. & 4 Univ. & 66 Univ. \\
\hline Total Self Development Courses & 4 & 3 & 9 & 0 & 7 & 23 \\
Average Self Development Courses per univ. & 0.50 & 0.14 & 0.32 & 0.00 & 1.75 \\
\hline
\end{tabular}

Young aspiring entrepreneurs have to learn about dealing with individuals, their problems and difficulties beside the common courses taught in business schools. While some business schools curricula taught risk analysis, very few courses covered subjects on crisis management and none of them touched on coping with failure. Risk analysis, a technique to minimize the probability of failure and optimize all factors considered, is an up-front consideration of factors that could impact the business negatively. Normally risk management deal with known factors, to be measured quantitatively and eventually supported by specific software packages. In other words, the aim of risk analysis is to prevent the failure. It is closed to Finance category. On the other hand, crisis management teaches how to manage emergency situations and how to ensure the continuity of business operations. It deals with uncertain factors mainly in qualitative dimensions and uses a wide range of scenarios to improve the adverse conditions that threaten the business. Crisis, however, is not in failure condition yet and crisis management is still on the business 
operations area. Therefore young entrepreneurs need another type of courses to anticipate the psychological or identity crisis as we put them in the Self-development category.

Indeed, courses in Self-development category are important for entrepreneurs to build their mental, self-leadership, self-awareness, self-image, etc. Unfortunately, only some courses shared those identity attributes to students as well as uncovered the difficulties in the entrepreneurs' world. Students need courses such as "Founder's Dilemma", "Dilemmas in Founding New Ventures", "Entrepreneurial Though and Action", "Your First Hundred Days", "Master Class (meet the entrepreneurs)", "Interaction with Industry Leaders", "Entrepreneurial Identity", "Entrepreneurship in Action", "Execution - Running your own company", "External Opportunities \& Threats", "Learning From Experience", "Tolerating and Learning from Failure", and "Ventures: Entrepreneurs Who Changed the World". Those courses were offered in the US and Europe business schools only.

\section{Discussion}

Discovery from exploring the sixty-six business schools' curricula, there were only few courses talking about network building as well as mental (entrepreneurship attitude) building. I wondered why the business schools in the US had those courses for the students while business schools in Asia and Australia region, Middle East and Africa region, and Latin and Central America region did not. Although the US value systems have supported the entrepreneurship and internalized a culture that no need for feeling shame after failure, the US business schools kindly kept providing mental building for their students. On the other hand, business schools in Asian, African and Latin America countries which have less value systems for entrepreneurship did not provide that kind of courses.

There were some resources which provided guidance for curriculum development related to overcoming the shame, such as Shepherd who studied educating entrepreneurship students about emotion and learning from failure [14], and Munshi who talked about surviving failure, overcoming internal factors, handling current failure, and learning from failure [15]. While Young investigated Facing Shame and Self-blame after Trauma [16], Shelton explored about the Sword of Trauma, how to remove the sword, healing the wound, and using our sword [17]. This survival manual provided many useful therapies for healing. There was also a special book by Shumake, a motivator, trainer, businessman, author and real estate master with real life business experiences, entitled "For Entrepreneurs who Considered Suicide when Business Got Tough!” [18].

In addition, the course also might cover obstacles in starting up a business, according to students in seven universities in Ireland. They were lack of courage $(60 \%$ of respondents) and fear of failure (54\% of respondents) [19]. Moreover, the course might build four conceptual constructs in the Chinese Entrepreneur Aptitude Scale (CEAS) [20], and autonomy and self-discipline as the basic principle of entrepreneurship education [21]. By preparing them, students might be able to anticipate and handle all pressures, depression, rage, shame, etc. in appropriate way.

\section{Conclusion}

In conclusion, business schools and entrepreneurship educators are called to respond to the missing link, i.e., the need of the students of entrepreneurship education programs to learn more about psychological-content courses, such as how to handle the shame in their society after the failure of their new ventures. The insights of this research may provide case studies to support the design of class-based learning in business schools to ensure that their graduates are prepared to embrace the advice of Smith and McElwee, i.e., "the flawed entrepreneur need not embrace the tragic storyline - there is life and a future after the fall!" [7].

\section{References}

1. Gots, J., Failure is not an Option. It's a Necessity, retrieved Aug 5, 2011 from http://bigthink.com/thinktank/failure-is-not-an-option-its-a-necessity.

2. Bedford, O. and Hwang, K.K., Guilt and Shame in Chinese Culture: A Cross-cultural Framework from the Perspective of Morality and Identity, Journal for the Theory of Social Behavior, 33(2), Jun 2003, pp. 127144.

3. Morrison, A.P., Shame, Ideal Self, and Narcissism, Contemporary Psychoanalysis, 19(2), 1983, pp. 295318.

4. Scheff, T.J., Shame and the Social Bond: a Sociological Theory, Sociological Theory, 18(1), 2000, pp. 84-99.

5. Poulson, C.F., Shame and Work, First Conference on Emotions in Organizational Life, San Diego (CA, USA), Aug 1998.

6. Wright, M. and Zahra, S., The Other Side of Paradise: Examining the Dark Side of Entrepreneurship, Entrepreneurship Research Journal, 1(3), 2011, pp. 1-5.

7. Smith, R. and McElwee, G., After the Fall, Developing a Conceptual Script-based Model of Shame in Narratives of Entrepreneurs in Crisis!, International Journal of Sociology and Social Policy, 31(1/2), 2011, pp. 91109.

8. WHO Regional Office for Europe, Suicide and Attempted Suicide in Young People, Report of a Working Group held in Zahreb (Yugoslavia) from 1 to 4 Oct 1973, in Suicide and Attempted Suicide (ed. Brooke, E.M.), Public Health Papers, 58, 1974, World Health Organization, Geneva, p.75.

9. Brooke, E.M. and Atkinson, M., Ascertainment of Deaths from Suicide, in Suicide and Attempted Suicide (ed. Brooke, E.M.), Public Health Papers, 58, 1974, World Health Organization, Geneva, p. 67.

10. Global Entrepreneurship Monitor, Entrepreneurial Behaviour and Attitudes, retrieved Sep 11, 2011 from http://www.gemconsortium.org/data/key-aps.

11. QS Quacquarelli Symonds, Top Business Schools, retrieved Sep 9, 2011 from http://www.topmba.com/ mba-rankings/global-200/2010/specializations/ entrepreneurship.

12. Buchanan, L., Best Courses 2011: Founders' Dilemmas, Inc. Magazine, April 2011, retrieved from http://www.inc.com/magazine/20110401/bestcourses-2011-founders-dilemmas-at-harvard-businessschool.html. 
13. Harvard Business School, Course Catalog - Founders' Dilemmas, retrieved Sep 6, 2011 from http://www.hbs. edu/coursecatalog/1676.html.

14. Shepherd, D.A., Educating Entrepreneurship Students about Emotion and Learning from Failure, Academy of Management Learning and Education, 3(3), 2004, pp. 274-287.

15. Munshi, P.P., Surviving Failure, Praxis Business Line's Journal on Management, 2(2), Aug 1998.

16. Young, K., Facing Shame and Self-blame after Trauma, retrieved Sep 11, 2011 from http://www.survivormanual. com/facing-shame-and-self-blame-after-trauma.

17. Shelton, A., Sword of Trauma, retrieved Sep 11, 2011 from http://www.survivormanual.com/sword-of-trauma.
18. Shumake, R.S., For Entrepreneurs who Considered Suicide when Business Got Tough!, Legacy Masterpieces Publishing, Clinton (MA, USA), 2005.

19. Birdthistle, N., Profiling the Entrepreneur: An Examination of Entrepreneurs in the Mid-west Region of Ireland, Journal of Economics and Organisation of Enterprise, 7(6/7/8), 2006, pp. 74-83.

20. Chen, W.Y., Weng, C.S., and Hsu, H.Y., A Study of the Entrepreneurship of Taiwanese Youth by the Chinese Entrepreneur Aptitude Scale, Journal of Technology Management in China, 5(1), 2010, pp. 26-39.

21. Van Gelderen, M., Autonomy as the Guiding Aim of Entrepreneurship Education, Education+Training, 52(8/9), 2010, pp. 710-721. 